\title{
Responsabilidad social y ambiental, análisis para tres microempresas en Ipiales, Colombia
}

\section{Social and environmental responsibility, analysis for three microenterprises in Ipiales - Colombia}

DOI: https://doi.org/10.17981/econcuc.40.2.2019.04

Artículo de investigación. Fecha de recepción: 15/02/2019. Fecha de aceptación: 20/07/2019

\author{
Alba Patricia Guerrero Guerrero \\ Centro de Desarrollo Empresarial SENA. (Tumaco, Colombia) \\ aguerrerog@sena.edu.co
}

Para citar este artículo:

Guerrero, A. (2019). Responsabilidad social y ambiental, análisis para tres microempresas en Ipiales, Colombia. Económicas CUC, 40(2). 53-69. DOI: http://dx.doi.org/10.17981/econcuc.40.2.2019.04

\section{Resumen}

Hoy día las empresas deben lograr un equilibrio entre su actividad económica que debe generar beneficios y creación de valor para sus socios y, los objetivos globales de la sociedad. Para calcular este equilibrio existen estándares internacionales como el Global Reporting Initiative (GRI), que ayuda a las organizaciones a dar cuenta sobre sus contribuciones propias para con el desarrollo sostenible a través de los modelos de Responsabilidad Social Empresarial (RSE) que ellas aplican. Es así, como se presenta un análisis del programa de Responsabilidad Social Empresarial con base al estándar internacional Global Reporting Initiative. La investigación realizada es de tipo descriptiva y analítica, previamente se generó un diagnostico empresarial a través del método FODA, posteriormente se analizó el estado actual de las organizaciones en cuanto a las actividades y prácticas empresariales desarrolladas siguiendo el estándar GRI. Los resultados permitieron generar una propuesta para el desarrollo de RSE de las empresas estudiadas, compuesta por estrategias e indicadores de gestión, por cada área empresarial, se establecieron acciones para el cumplimiento del estándar GRI. Se concluye que esta propuesta permitirá a las empresas realizar un reporte de información ambiental y social bajo el estándar GRI.

Palabras clave: DOFA; Estrategias; indicadores; iniciativa de informe global; responsabilidad social empresarial; responsabilidad ambiental empresarial; GRI

\begin{abstract}
Today companies must strike a balance between their economic activity that must generate benefits and value creation for their partners and the overall objectives of society. To calculate this balance, there are international standards such as the Global Reporting Initiative (GRI), which helps organizations to account for their own contributions to sustainable development through the Corporate Social Responsibility (CSR) models that they apply. . This is how an analysis of the Corporate Social Responsibility program based on the international standard Global Reporting Initiative is presented. The research carried out is descriptive and analytical, previously a business diagnosis was generated through the SWOT method, then the current status of organizations in terms of business activities and practices developed following the GRI standard was analyzed. The results allowed generating a proposal for the development of CSR of the companies studied, consisting of strategies and management indicators, for each business area, actions were established for compliance with the GRI standard. It is concluded that this proposal will allow companies to make a report of environmental and social information under the GRI standard.
\end{abstract}

Keywords: SWOT; Strategies; indicators; global reporting initiative; corporate social responsibility; GRI 


\section{INTRODUCCIÓN}

González, Galeano y Trejos (2015) expresan como "con la finalización de la Segunda Guerra Mundial, el orden global entró en proceso de transformación hacia un nuevo precepto mundial que rigió las reglas de juego" (p. 80), como parte de ello nace la responsabilidad social que ha sido originada a partir de las exigencias de la sociedad para con las organizaciones, "el nuevo escenario mundial de globalización ha hecho que las organizaciones se transformen, adapten y desempeñen nuevos roles" (Chumaceiro, Hernández y Chirinos, 2016, p. 54). Al respecto, Reyes, Hernández, Chumaceiro y Cadrazco (2016) comentan como las múltiples iniciativas a nivel mundial han hecho para sensibilizar a las sociedades en general, así entonces se habla de Responsabilidad social (RS), siendo importante entender que "es realizada por las organizaciones, tanto dentro como fuera de ellas y es concebida para garantizar el equilibrio de todas las personas que forman parte de su capital humano" (Sisiruca y Salazar, 2014, p. 81), equilibrio, social, económico, medioambiental, entre otros.

Ahora bien, el Centro Sur Colombiano de Logística Internacional-CSCLI tiene entre sus procesos misionales, el emprendimiento y la creación de empresas, de hecho, a través del "Fondo Emprender" se han constituido un gran número de entidades que responden a diferentes modelos de negocio y desarrollan actividades industriales, de servicios y comerciales.

Estas cuentan con el apoyo de todo un equipo técnico del CSLI que les prestan asesoría y orientación en temas de cumplimiento de metas de generación de empleo, nivel de ingresos, sostenibilidad económica y demás indicadores financieros y de gestión como requisitos para continuar ope- rando. Hoy en día como lo describe (Haro, Alarcón y Caba, 2012), las empresas tienen que asumir una serie de compromisos para lograr una convivencia en armonía entre sus actividades licitas, encaminadas a obtención de beneficios así como la creación de valor para sus socios, y los objetivos globales de la sociedad. Estas empresas no cuentan con un programa de Responsabilidad Social Empresarial - RSE (Vélez, 2011), bajo el estándar internacional GRI - que les ayude a fortalecer sus procesos misionales, estratégicos y de apoyo, informes que dan cuenta de la contribución de la empresa al desarrollo sostenible (Fernández y Larrinaga, 2007), y optimando algunas prácticas responsables que pueden mejorar la competitividad en las MyPE's, en estas cuatro áreas: aumento de ingresos, reducción de costos, aumentos de productividad, reducción de riesgos y aumento del valor de los activos (Vives \& Peinado-Vara, 2011).

Por tanto, inicialmente se parte de un diagnóstico a través del método FODA (Fortalezas-Oportunidades-Debilidades-Amenazas) (Ponce, 2007), seguidamente a esto se hace una análisis en cuanto a las actividades y prácticas empresariales desarrolladas y el impacto que generan en términos ambientales y sociales (Del Castillo, Cancino, Martínez \& Corona, 2013). Para en una segunda parte realizar alternativas, indicadores y acciones en cuanto a RSE guiados bajo el estándar internacional GRI, que permitan posteriormente hacer un reporte de la información social y ambiental en cada una de las empresas (Bour, 2012).

\section{Metodología}

El tipo de investigación realizada es de tipo descriptiva y analítica, y como una parte preliminar se hizo la invitación a las empresas registradas en SBDC del CSCLI con 
área de influencia del municipio de Ipiales, de las cuales se vieron interesadas tres de las seis empresas relacionadas en la base de datos proporcionada por emprendimiento a SENNOVA.

\section{Población}

Se realiza la intervención específica a tres empresas ubicadas en la zona de influencia de Ipiales, las cuales son: Tecnovida SAS (vivero), Hato El Paraíso (producción y comercialización de leche y ganado vacuno) y Frazabella Factory (fabricación y comercialización de ropa de cama). De las cuales los gerentes, los jefes administrativos y/o, jefes operativos, contestan y hacen el acompañamiento a las visitas realizadas por los profesionales del CSCLI.

\section{Técnicas e instrumentos}

para la recolección de datos

La recolección de datos se realizó en un periodo de cinco meses en parte del primer y parte del segundo semestre del año 2018, con preguntas de tipo abierta por ser requerido un basto conocimiento desde el punto de vista de los involucrados.

Para el cumplimiento del primer objetivo de diagnóstico se realizó un primer momento de entrevistas con un cuestionario de 46 preguntas, con el fin de realiza un primer acercamiento para el conocimiento de la empresa. Un segundo momento se hizo a través de una visita de observación en las instalaciones de la empresa teniendo como parámetro analizar las seis áreas de la empresa y los mismos 46 items de las preguntas (mercado, ventas y servicios, producción, administración y finanzas, investigación y desarrollo, y recursos humanos). En un tercer momento con base en entrevistas y observación directa, se diagnostica a través de listas de chequeo con 147 ítems, el cumplimiento de análisis de estándares GRI, universal, ambiental y social (Rebelo \& Marques, 2016).

La información obtenida se consolida en el desarrollo de una matriz DOFA y el informe del diagnóstico para cada empresa.

Para la segunda parte se realizó una metodología tomando como base el GRI, donde se tienen en cuenta tres estándares con sus respectivos subíndices (o ítems); los estándares universales tienen seis subíndices; los estándares ambientales están representada por ocho subíndices, los cuales cubren aspectos de diversa índole en materia medioambiental; y los estándares sociales que cuentan con un numero de 19 subíndices de los cuales solo se analiza los 10 más relevantes.

Finalmente se desarrolla una propuesta gestionada así: una matriz con 24 estrategias DO, FA, FO, DA por cada una de las seis áreas de la empresa con una tabla de doce indicadores en cada área (Silva, 2009), y en último lugar se realiza un cuadro de acciones de cada uno de los subíndices, donde se relacionan los indicadores, acciones, medio de verificación e impactos con base al estándar GRI (universales, ambientales y sociales) (Silva \& João, 2012), esto como insumo para la realización de reportes posteriores de información social y ambiental (Gómez y Quintanilla, 2012).

\section{Resultados}

\section{Diagnostico}

Se realizó la consolidación de la información del diagnóstico a través del método FODA por medio del cual se identificó, y analizó el desarrollo de las actividades de las tres empresas que impactan en la sociedad y en el ambiente. 


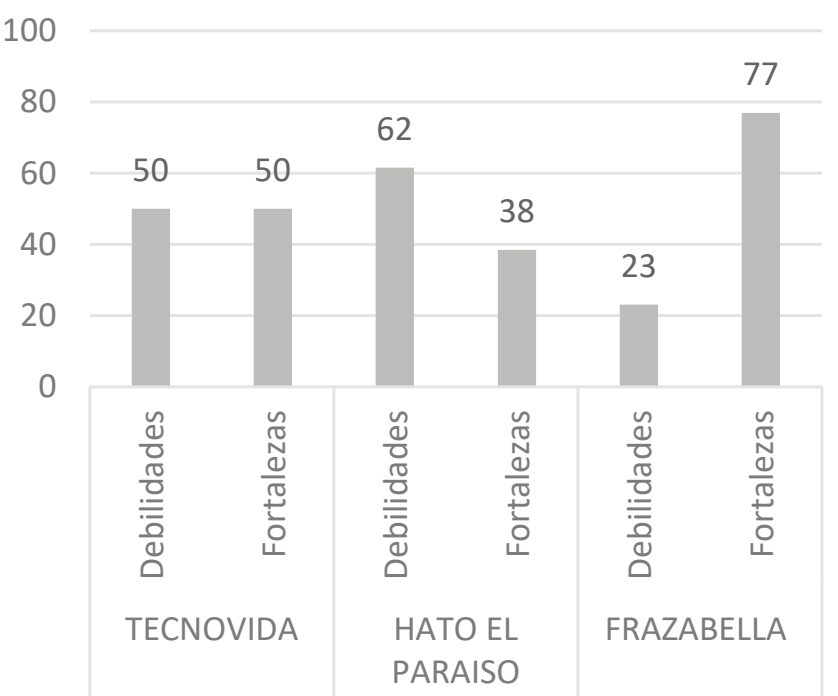

Figura 1. Diagnostico interno por empresas - Porcentual

Fuente: Elaboración propia.

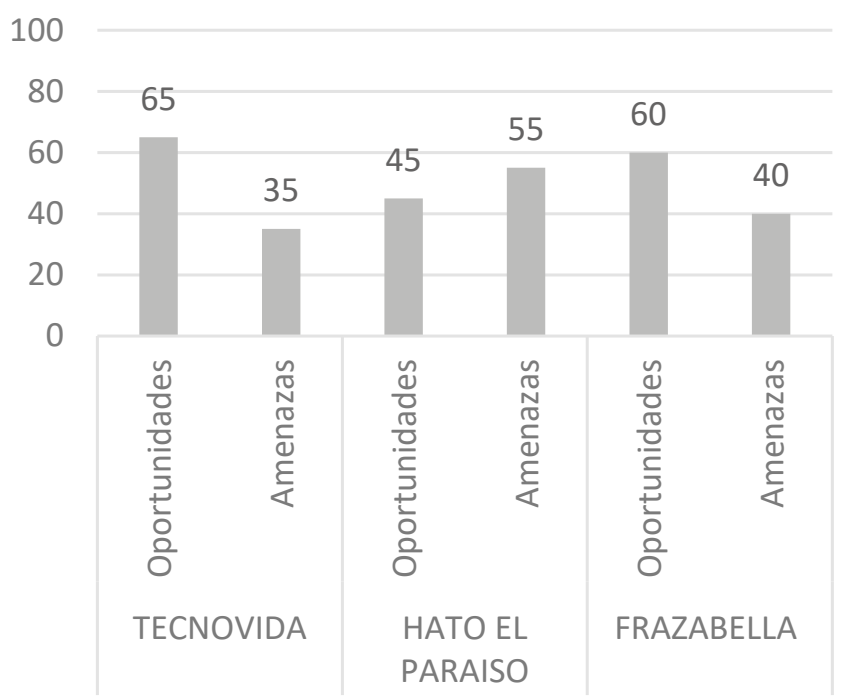

Figura 2. Diagnostico externo por empresas - Porcentual

Fuente: Elaboración propia.

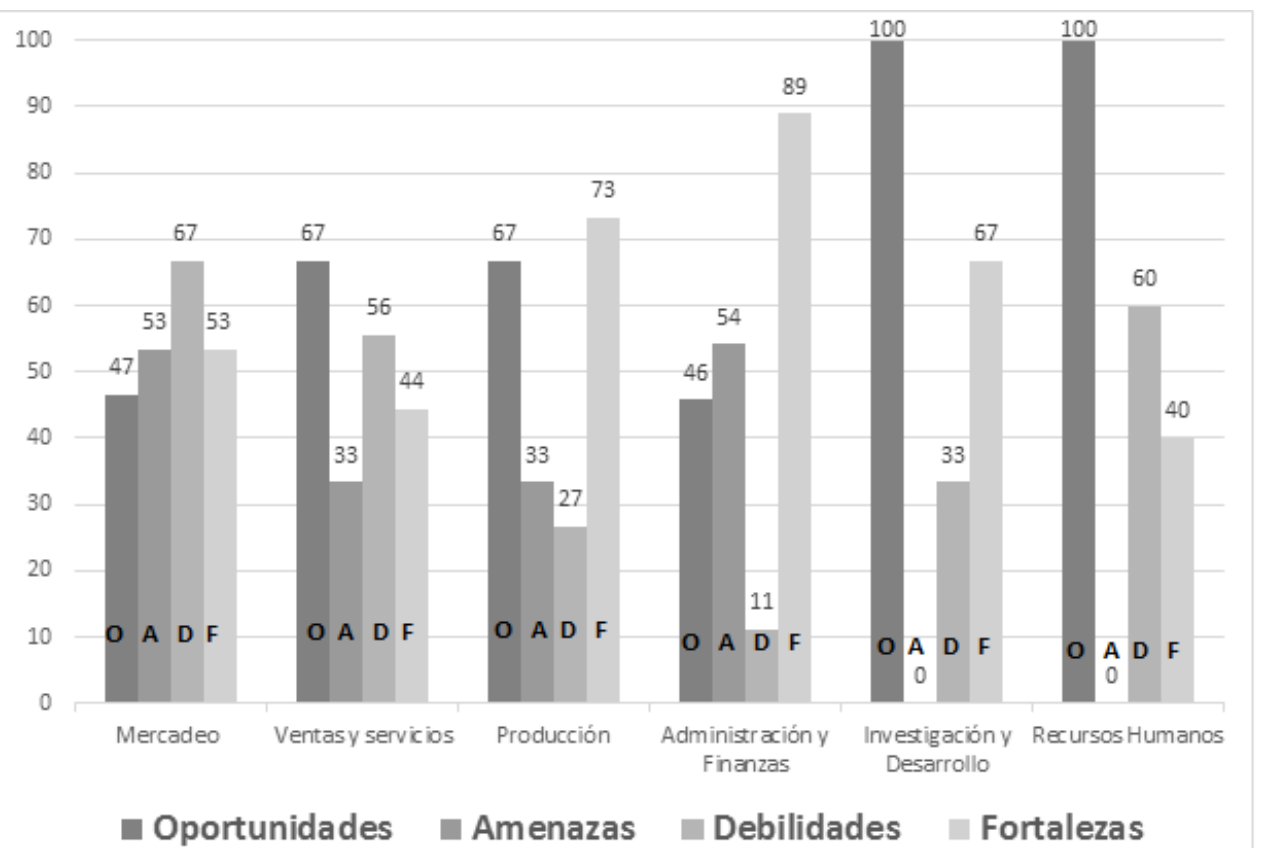

Figura 3. DOFA de las tres empresas en cada área.

Fuente: Elaboración propia.

La Figura 1 muestra el diagnóstico interno, el porcentaje de Debilidades (D) versus las Fortalezas (F) en cada una de las tres empresas beneficiadas, por ejemplo, la empresa Tecnovida, tiene un equilibrio entre las debilidades (50\%) y fortalezas (50\%); la empresa Hato El Paraíso tiene más marcadas las debilidades (62\%) y la empresa Frazabella muestra mayor solidez con una proporción de fortalezas del 77\%. De la misma manera se realiza el diagnostico externo, como se observa en la Figura 2, en la empresa Tecnovida y Frazabella, hay mayores oportunidades (65\% y $60 \%$ respectivamente), en tanto en la empresa Hato El Paraíso se perciben en mayor proporción las amenazas (55\%). 
En la Figura 3 se muestra un compendio del análisis DOFA de las tres empresas participantes y en cada una de las áreas: la primera columna muestra las oportunidades y la segunda columna las amenazas, por ejemplo, existen más amenazas que oportunidades en el área de mercadeo (53\%) y en el área de administración y finanzas (54\%), y en las otras áreas se perciben mayores oportunidades que amenazas. La misma figura muestra en la tercera columna las debilidades y la cuarta columna las fortalezas de las empresas, por ejemplo, existen más debilidades en las áreas de mercadeo (67\%), ventas y servicios (56\%) y recursos humanos (60\%), que en las otras áreas.

Los empresarios también perciben las oportunidades en cuanto a investigación y desarrollo y que cuentan con grandes fortalezas administrativas y financieras al igual que productivas.

De la misma forma, se realizó la discriminación del ítem de debilidades y fortalezas, en la que se hallaron debilidades como: la baja realización de eventos de superación personal; incentivos y contratos suscritos con clientes, y proveedores de manera formal; no hay existencia de vehículo propio para las ventas. En las fortalezas sobresalen: la capacitación del personal, los indicadores de calidad de producto, el buen ambiente con los proveedores y los buenos procesos de innovación y buenos productos.

Por otra parte, se identificaron como amenazas: el aumento y sobre costo de insumos, la afectación del precio por el tratado de libre comercio (TLC), la competencia desleal por calidad y no cantidad. En las oportunidades se encontró: la mano de obra calificada en la zona, la existencia de entidades financieras para investigación, cuentan con convocatorias para inversión, el apoyo del
SENA y otras entidades gubernamentales, entre otras.

En un segundo momento se consolidaron los indicadores partir de las condiciones expuestas por la GRI denominado "Cuestionario - 102 Divulgaciones Generales", "300 - Ambientales", "400 - Sociales", que permiten hacer un reporte en cuanto al Programa RSE - utilizando la opción de reporte integrado básico del estándar internacional GRI de los componentes ambientales y sociales.

Para esta segunda parte, se han estimado los diferentes subíndices sobre la divulgación de información, para cada una de las dimensiones estudiadas (estándares universales, ambiental y social) (Pérez, Haro, Saraite y Gálvez (2016).

En la Tabla 1 se muestra cuáles son los subíndices que cumplen con mayor frecuencia las empresas, en cuanto a los estándares universales, ambientales y sociales. En los subíndices de los estándares universales, la empresa Frazabella es la que más ítems cumple, en los estándares ambientales se observó como la empresa de mayor cumplimiento es el Hato El Paraíso, y en los subíndices de los estándares sociales, se aprecia a la empresa Frazabella como la que mayormente cumple.

En una síntesis de los subíndices de los estándares de las tres empresas participantes, se pudo determinar, el cumplimiento en los subíndices universales en el ítem denominado perfil de la organización y no cumplen en la práctica de los informes de sostenibilidad de la empresa como lo ilustra la Figura 4. Las tres empresas cumplen en los subíndices ambientales como energía y efluentes-residuos, como muestra la Figura 5; y en los subíndices sociales cumplen en el de trabajo infantil y trabajo forzado, como lo muestra la Figura 6. 
TABla 1.

Cumplimiento por estándares e ítem.

\begin{tabular}{|c|c|c|c|c|}
\hline ID & Ítem - subíndice & Tecnovida & Hato El Paraíso & Frazabella \\
\hline 100 & Estándares universales - D. generales. & & & \\
\hline \multirow{6}{*}{102} & Perfil de la organización & & & \\
\hline & Estrategia & & - & \\
\hline & Ética e integridad & & - & \\
\hline & Gobierno & - & - & \\
\hline & Participación de los interesados & - & - & \\
\hline & Practica de informes & - & - & - \\
\hline 300 & Estándares ambientales & & & \\
\hline 301 & Materiales & & & \\
\hline 302 & Energía & & & - \\
\hline 303 & agua y efluentes & & & \\
\hline 304 & Biodiversidad & - & & \\
\hline 305 & Emisiones & - & - & - \\
\hline 306 & Efluentes y Residuos & - & 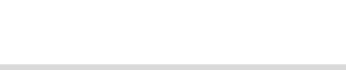 & - \\
\hline 307 & Cumplimiento ambiental & & & \\
\hline 308 & Evaluación ambiental del proveedor & - & - & - \\
\hline 400 & Estándares Sociales & 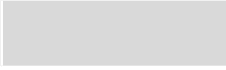 & 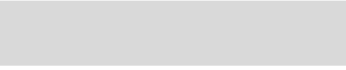 & \\
\hline 401 & Empleo & - & - & 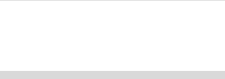 \\
\hline 402 & Relaciones laborales / de gestión & - & - & 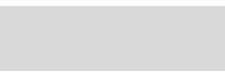 \\
\hline 403 & Seguridad y salud laboral & - & - & - \\
\hline 404 & Entrenamiento y educación & - & 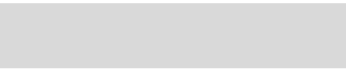 & \\
\hline 405 & Diversidad e igualdad de oportunidades & - & - & \\
\hline 406 & No discriminación & - & - & \\
\hline 407 & Libertad de asociación y negociación colectiva & - & - & - \\
\hline 408 & Trabajo infantil & & & \\
\hline 409 & Trabajo Forzado u Obligatorio & & & \\
\hline 410 & Prácticas de seguridad & - & & \\
\hline 411 & Derechos de los Pueblos Indígenas & & - & - \\
\hline 412 & Evaluación de derechos humanos & - & - & - \\
\hline 413 & Comunidades locales & - & - & - \\
\hline 414 & Evaluación social del proveedor & - & - & - \\
\hline 415 & Política pública & - & - & - \\
\hline 416 & Salud y seguridad del cliente & - & - & - \\
\hline 417 & Marketing y etiquetado & - & - & \\
\hline 418 & Privacidad del cliente & - & - & - \\
\hline 419 & Cumplimiento Socioeconómico & & & \\
\hline
\end{tabular}

Fuente: Elaboración propia. 
- Perfil de la

organización

Estrategia

Ética e

integridad

- Gobierno

Participación de los interesados

Practica de

informes

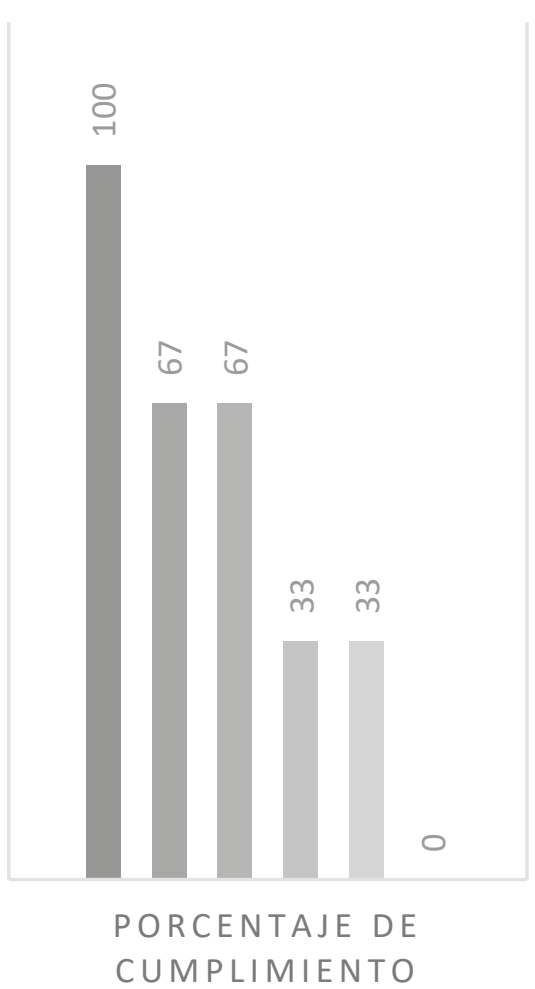
agua y efluentes
Biodiversidad
Emisiones
Efluentes y
Residuos
Cumplimiento
ambiental

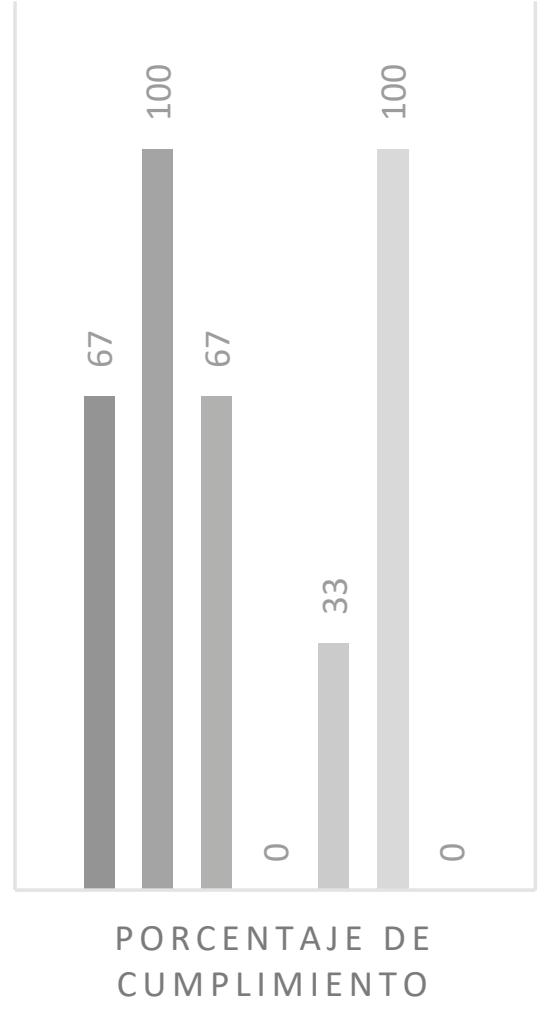

Figura 5. Cumplimiento estándares ambientales.

Fuente: Elaboración propia.
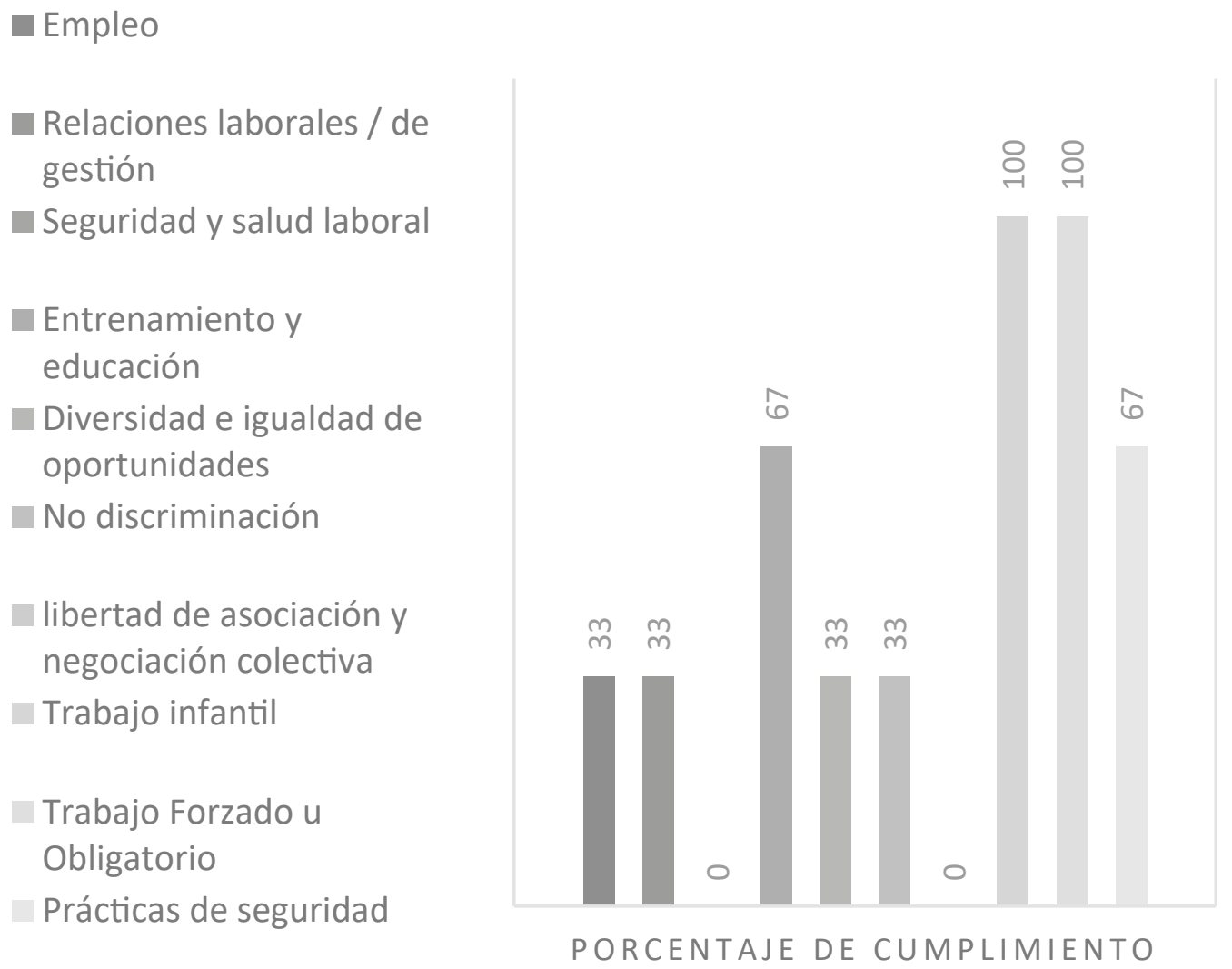

Figura 6. Cumplimiento estándares sociales.

Fuente: Elaboración propia. 


\section{Propuesta}

Como propuesta de implementación del programa de Responsabilidad Social Empresarial - RSE, se realizaron diferentes estrategias en las seis áreas de la empresa, los cuales les permitan determinar, un horizonte donde se minimicen las de- bilidades y amenazas, y maximicen las fortalezas y oportunidades, para ello se hace una propuesta de 24 estrategias, las cuales se describen en la Tabla 2, teniendo en cuenta que las estrategias propuestas, se acomodan a los recursos con los que cuentan las empresa para realizarlas.

TABLA 2.

Estrategias por área de la empresa.

\begin{tabular}{|c|c|c|}
\hline $\begin{array}{c}\text { Área de la } \\
\text { empresa }\end{array}$ & $\begin{array}{c}\text { Tipo de } \\
\text { estrategia }\end{array}$ & Estrategia \\
\hline \multirow{3}{*}{ Mercadeo } & $\mathrm{DO}$ & $\begin{array}{l}\text { Determinar oportunidades de exportación y después de una plena } \\
\text { investigación de mercados, se debe planear la manera de incrementar la } \\
\text { capacidad de producción y así brindar mejores beneficios a la comunidad y } \\
\text { trabajadores. }\end{array}$ \\
\hline & FA & Programación de eventos especiales de promoción de productos ofrecidos. \\
\hline & $\mathrm{FO}$ & $\begin{array}{l}\text { Aprovechando la calidad del producto y la buena relación con los proveedores } \\
\text { se puede abrir el mercado al exterior innovando en exportación. }\end{array}$ \\
\hline \multirow{5}{*}{$\begin{array}{l}\text { Ventas y } \\
\text { servicios }\end{array}$} & $\mathrm{DO}$ & $\begin{array}{l}\text { Búsqueda de un cliente directo para comercializar, con un pago a buen } \\
\text { precio. }\end{array}$ \\
\hline & DO & $\begin{array}{l}\text { Realizar un portafolio de productos para mejorar la comercialización en } \\
\text { otros municipios cercanos. }\end{array}$ \\
\hline & $\mathrm{DO}$ & $\begin{array}{l}\text { Determinar la mejor opción en cuanto a crédito para acceder a un vehículo, } \\
\text { posibilitando la mejora en la comercialización. }\end{array}$ \\
\hline & $\mathrm{FO}$ & $\begin{array}{l}\text { Resaltar las especificaciones del proceso de producción en el producto, } \\
\text { prestigio, conocimiento del producto, en los programas de promoción y } \\
\text { publicidad que se implementan en un contacto más directo con el cliente con } \\
\text { información vía mail. }\end{array}$ \\
\hline & $\mathrm{DA}$ & $\begin{array}{l}\text { Mantener la calidad del producto, mejorar la calidad del servicio posventa } \\
\text { y la especialización del mismo realizando encuestas de satisfacción para } \\
\text { verificar las expectativas de los clientes. }\end{array}$ \\
\hline \multirow{4}{*}{ Producción } & DO. & $\begin{array}{l}\text { Mejorar infraestructura para aumentar la capacidad realizando } \\
\text { participación a convocatorias de inversión de tipo local, regional o nacional. }\end{array}$ \\
\hline & DO. & $\begin{array}{l}\text { Con el apoyo del SENA y la colaboración de un técnico mejorar los procesos } \\
\text { productivos para realizar la disminución de pérdidas de insumos y producto. }\end{array}$ \\
\hline & FA & $\begin{array}{l}\text { Buscar apoyo con político del sector para realizar mejoras o mantenimiento } \\
\text { en la carretera que comunica a la zona rural del municipio de los municipios } \\
\text { de cobertura }\end{array}$ \\
\hline & $\mathrm{DA}$ & $\begin{array}{l}\text { Buscar alianzas con empresas afines para acceder a mercados más grandes } \\
\text { y cumplir con parámetros de calidad y cantidad. }\end{array}$ \\
\hline
\end{tabular}




\begin{tabular}{|c|c|c|}
\hline $\begin{array}{l}\text { Área de la } \\
\text { empresa }\end{array}$ & $\begin{array}{l}\text { Tipo de } \\
\text { estrategia }\end{array}$ & Estrategia \\
\hline \multirow{7}{*}{$\begin{array}{l}\text { Administración } \\
\text { y finanzas }\end{array}$} & DO. & $\begin{array}{l}\text { Con el apoyo del SENA podrá lograr la implementación en cuanto a la } \\
\text { plataforma estratégica definida y contar con la capacitación requerida para el } \\
\text { personal de trabajo. }\end{array}$ \\
\hline & DO. & Acoplamiento de un paquete contable para mejorar los procesos financieros. \\
\hline & FA & $\begin{array}{l}\text { Realizar un análisis de costos detallado para permitir mantener un precio } \\
\text { competitivo dentro del mercado. }\end{array}$ \\
\hline & FA & Buscar alianzas con proveedores para mejorar los precios de los insumos. \\
\hline & FA & $\begin{array}{l}\text { Realizar procesos de asociatividad con productores, para mejorar la situación } \\
\text { de precios tanto en la compra de insumos como en la venta del producto. }\end{array}$ \\
\hline & FO & $\begin{array}{l}\text { Afianzamiento de los conocimientos del gerente para mejorar procesos } \\
\text { administrativos, contables y comerciales para lograr un buen manejo y } \\
\text { desarrollo. }\end{array}$ \\
\hline & FO & $\begin{array}{l}\text { Implementación del software para el manejo y la administración la empresa } \\
\text { lograra aumentar su actividad. }\end{array}$ \\
\hline \multirow{2}{*}{$\begin{array}{l}\text { Investigación y } \\
\text { Desarrollo }\end{array}$} & FA & $\begin{array}{l}\text { Realizar procesos de investigación e innovación con el fin de mejorar procesos } \\
\text { de producción. }\end{array}$ \\
\hline & $\mathrm{FO}$ & $\begin{array}{l}\text { Participar en la convocatoria de fomento a la innovación para aumentar la } \\
\text { competitividad a través del mejoramiento de los productos. }\end{array}$ \\
\hline \multirow{3}{*}{$\begin{array}{l}\text { Recursos } \\
\text { humanos }\end{array}$} & DO. & Realizar un manual de procesos y funciones dentro de la empresa. \\
\hline & DO. & $\begin{array}{l}\text { Buscar asesoría debido a que se deben ajustar los contratos, regidos a la ley } \\
\text { para evitar sanciones. }\end{array}$ \\
\hline & $\mathrm{DA}$ & $\begin{array}{l}\text { Afianzar la capacitación de los empleados a través de la articulación con } \\
\text { la alcaldía o entidad afín, para mejorar tanto calidad como cantidad de } \\
\text { producción. }\end{array}$ \\
\hline
\end{tabular}

Fuente: Elaboración propia.

Igualmente se realiza la estimación de indicadores (Tabla 3), que permitan medir el impacto en las empresas y con ello puedan realizar acciones de control, toma de decisiones posteriores y el mejoramiento en cada una de las seis áreas.

Teniendo como bases el estándar internacional del Global Reporting Initiative (GRI) y con respecto a lo observado y analizado en las empresas, se propone realizar acciones enfocadas a mejorar la sostenibilidad de la empresa, con el fin de dar cuenta a la sociedad de las operaciones con responsabilidad ambiental y social, siendo este un parámetro de competitividad, en un entorno complejo (Tabla 4, Tabla 5 y Tabla 6).
Según el estudio realizado por Rodríguez y Ríos (2016) se determina que los reportes de sostenibilidad bajo la metodología GRI, versión 4 en Colombia, de 87 empresas, después de aplicar la escala de evaluación de los tres niveles de sostenibilidad, obtuvieron en las tres dimensiones, el mayor porcentaje en el nivel de sostenibilidad "en Desarrollo". A diferencia de lo encontrado en las tres empresas creadas por SBDC, las cuales requieren mayor atención en cuanto a su responsabilidad ambiental y social. Con respecto al análisis de la Sostenibilidad por dimensiones, en el estudio de Rodríguez y Ríos (2016), encontró que las empresas, dependiendo del sector al que pertenezcan, desarrollan más la dimensión a la cual impacten en el ejercicio 
TABLA 3.

Tabla de indicadores por áreas de la empresa.

\begin{tabular}{|c|c|c|c|c|}
\hline $\begin{array}{c}\text { Áreas } \\
\text { funcionales }\end{array}$ & $\begin{array}{l}\text { Nombre del } \\
\text { Indicador }\end{array}$ & Formula & Impacto & Frecuencia \\
\hline \multirow{2}{*}{ Mercadeo } & $\begin{array}{l}\text { Cumplimiento a } \\
\text { compradores }\end{array}$ & $\begin{array}{l}\text { Total de pedidos entregados } \\
\text { a tiempo/Total de pedidos } \\
\text { recibidos por periodo x } 100\end{array}$ & $\begin{array}{l}\text { Llevar a cabo la política de } \\
\text { cumplimiento que quiere } \\
\text { la empresa }\end{array}$ & Mensual \\
\hline & $\begin{array}{l}\text { Detección de } \\
\text { nuevos mercados }\end{array}$ & No de nuevos clientes & $\begin{array}{l}\text { Mejorar las ventas } \\
\text { especialmente en picos de } \\
\text { producción altos }\end{array}$ & Semestral \\
\hline \multirow{2}{*}{$\begin{array}{l}\text { Ventas y } \\
\text { servicios }\end{array}$} & $\begin{array}{l}\text { Relación ventas } \\
\text { reales y ventas } \\
\text { estimadas }\end{array}$ & $\begin{array}{l}\text { Ventas reales/Ventas } \\
\text { estimadas }\end{array}$ & $\begin{array}{l}\text { Determinar si las } \\
\text { estrategias de mercadeo } \\
\text { están dando los resultados } \\
\text { esperados }\end{array}$ & Mensual \\
\hline & $\begin{array}{l}\text { Grado de } \\
\text { satisfacción de } \\
\text { clientes externos }\end{array}$ & $\begin{array}{l}\text { No. Clientes satisfechos/ } \\
\text { Total de clientes }\end{array}$ & $\begin{array}{l}\text { Mayor satisfacción del } \\
\text { cliente }\end{array}$ & Semestral \\
\hline \multirow{2}{*}{ Producción } & $\begin{array}{l}\text { Desperdicio de la } \\
\text { producción }\end{array}$ & $\begin{array}{l}\text { Total de productos sin } \\
\text { defectos periodo/total de } \\
\text { producto producido }\end{array}$ & $\begin{array}{l}\text { Disminución de costos de } \\
\text { producción }\end{array}$ & Mensual \\
\hline & $\begin{array}{l}\text { Cumplimiento } \\
\text { programa de } \\
\text { producción }\end{array}$ & $\begin{array}{l}\mathrm{N}^{\circ} \text { de plantas nuevas por } \\
\text { período de producción }\end{array}$ & $\begin{array}{l}\text { Lograr escalonamiento } \\
\text { de la producción y } \\
\text { cumplimiento a los clientes }\end{array}$ & Semestral \\
\hline \multirow{2}{*}{$\begin{array}{l}\text { Admon y } \\
\text { finanzas }\end{array}$} & $\begin{array}{l}\text { Porcentaje de } \\
\text { facturas cobradas }\end{array}$ & $\begin{array}{l}\text { No de facturas cobradas/ } \\
\text { Total de facturas }\end{array}$ & $\begin{array}{l}\text { Mejoramiento en capital de } \\
\text { trabajo }\end{array}$ & Quincenal \\
\hline & Capital de trabajo & $\begin{array}{l}\text { Capital de trabajo/Activo } \\
\text { circulante }\end{array}$ & $\begin{array}{l}\text { Mejoramiento en capital de } \\
\text { trabajo }\end{array}$ & Mensual \\
\hline \multirow{2}{*}{$\begin{array}{l}\text { Investigación } \\
\text { y Desarrollo }\end{array}$} & $\begin{array}{l}\text { Inventarios } \\
\text { de nuevas } \\
\text { investigaciones }\end{array}$ & $\begin{array}{l}\text { No de nuevas } \\
\text { investigaciones }\end{array}$ & $\begin{array}{l}\text { Indicé de Generación de } \\
\text { Empleo Directo }\end{array}$ & Semestral \\
\hline & $\begin{array}{l}\text { Concordancia } \\
\text { calidad de los } \\
\text { productos }\end{array}$ & $\begin{array}{l}\text { Total de productos calidad } \\
\text { superior/total de producto } \\
\text { producido }\end{array}$ & $\begin{array}{l}\text { Mejoramiento en la } \\
\text { calidad, mejora pago por } \\
\text { los productos }\end{array}$ & Mensual \\
\hline \multirow{2}{*}{$\begin{array}{l}\text { Recursos } \\
\text { humanos }\end{array}$} & $\begin{array}{l}\text { Grado de } \\
\text { satisfacción de } \\
\text { clientes internos }\end{array}$ & $\begin{array}{l}\text { No. Clientes satisfechos/ } \\
\text { Total de clientes }\end{array}$ & Mayor productividad & Semestral \\
\hline & $\begin{array}{l}\text { Capacitación } \\
\text { cliente interno }\end{array}$ & $\begin{array}{l}\text { No. Capacitaciones } \\
\text { realizadas }\end{array}$ & $\begin{array}{l}\text { Mejoramiento en la } \\
\text { productividad }\end{array}$ & Trimestral \\
\hline
\end{tabular}

Fuente: Elaboración propia.

de su actividad corporativa. Es así, como las ONG presentan un nivel de sostenibilidad madura en la dimensión social, mientas que las corporaciones bancarias lo presentan en la dimensión económica. Para el caso de estudio de esta investigación se puede decir que para las dos empresas agropecuarias estudiadas la dimensión en la que más cumplen son las ambientales al ser muchas las acciones relacionadas en la Tabla 6, llevandose a cabo; y la empresa Frazabella es más tendiente a cumplir los estándares sociales con acciones relacionadas en la Tabla 7 de estándares sociales. 
TABLA 4.

Acciones divulgaciones universales - 100

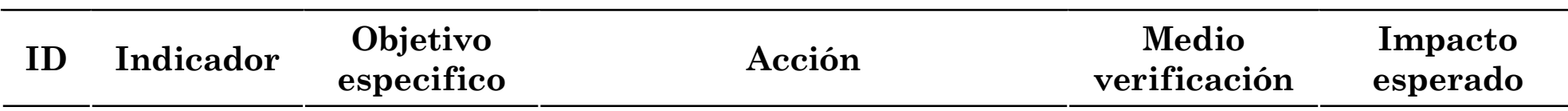

Determinación de Actividades, marcas, productos y servicios, Perfil de la Determinar Ubicación de la sede, Ubicación de organización el perfil de la organización las operaciones, Mercados servidos, Información sobre empleados y otros trabajadores, cadena de suministro, Principio de precaución o enfoque

\begin{tabular}{|c|c|c|c|c|}
\hline Estrategia & $\begin{array}{l}\text { Establecer } \\
\text { la estrategia } \\
\text { de la } \\
\text { organización }\end{array}$ & $\begin{array}{l}\text { Declaración del máximo responsable } \\
\text { de la toma de decisiones en cuanto } \\
\text { a las estrategias de la organización } \\
\text { y determinar los principales } \\
\text { impactos, riesgos y oportunidades. }\end{array}$ & $\begin{array}{l}\text { Matriz de } \\
\text { estrategias } \\
\text { - plan } \\
\text { estratégico. } \\
\text { Matriz de } \\
\text { impactos } \\
\text { riesgos y } \\
\text { oportunidades. }\end{array}$ & $\begin{array}{l}\text { Determina que } \\
\text { acciones llevar } \\
\text { acabo para el } \\
\text { mejoramiento } \\
\text { productivo y } \\
\text { competitivo de } \\
\text { la empresa. } \\
\text { Área: } \\
\text { administración } \\
\text { y finanzas }\end{array}$ \\
\hline $\begin{array}{l}\text { Ética e } \\
\text { integridad }\end{array}$ & $\begin{array}{l}\text { Construir el } \\
\text { código de ética } \\
\text { e integridad } \\
\text { de la } \\
\text { organización. }\end{array}$ & $\begin{array}{l}\text { Realización de manuales de } \\
\text { ética donde se presenten y se } \\
\text { pongan en práctica los valores, } \\
\text { principios, estándares y normas } \\
\text { de comportamiento, además de } \\
\text { mecanismos de asesoramiento e } \\
\text { inquietudes sobre ética. }\end{array}$ & $\begin{array}{l}\text { Manual de } \\
\text { ética. }\end{array}$ & $\begin{array}{l}\text { Mejoramiento } \\
\text { de las relaciones } \\
\text { internas y } \\
\text { externas entre } \\
\text { los involucrados. } \\
\text { Área: Recursos } \\
\text { Humanos }\end{array}$ \\
\hline
\end{tabular}

\begin{tabular}{|l|l|}
\hline Gobierno & $\begin{array}{l}\text { Mejorar la } \\
\text { gobernabilidad } \\
\text { de la } \\
\text { organización. }\end{array}$
\end{tabular}

Disposición de una Estructura de gobierno; Delegación de autoridad; Responsabilidad a nivel ejecutivo de temas económicos, ambientales y sociales; Consultar a las partes interesadas sobre temas económicos, ambientales y sociales; Composición del máximo órgano de gobierno y sus comités; Evaluación del desempeño del máximo órgano de gobierno; Identificación y gestión de impactos económicos, ambientales y sociales; Comunicación de preocupaciones críticas; Políticas de remuneración

Especificación de la lista de grupos

Participación de los interesados

Perfeccionar las relaciones e interés de los involucrados. de partes interesadas, Convenios colectivos, Identificación y selección de las partes interesadas, Enfoque para el compromiso de los interesados, Temas clave y preocupaciones planteados.

Definición el contenido del informe y el tema Límites
Informe de sostenibilidad
Mejoramiento de la imagen empresarial

Área: ventas y servicios

Humanos

Empresa con

Actas de mejoramiento a nivel de gobierno e interesados en temas económicos, ambientales y sociales. mejor toma de decisiones a nivel de autoridad en temas económicos, ambientales y sociales.

Área: administración $\mathrm{y}$ finanzas

Actas de reuniones e informes de las necesidades de los involucrados.

Informe de sostenibilidad
La empresa apunta hacia la satisfacción de los involucrados. Área: ventas y servicios

Mejoramiento de la imagen empresarial Área: mercadeo

Fuente: Elaboración propia. 
TABLA 5.

Acciones divulgaciones ambientales -300

\begin{tabular}{|l|l|l}
\hline ID & Indicador & $\begin{array}{c}\text { Objetivo } \\
\text { especifico }\end{array}$ \\
\hline 301 & Materiales & $\begin{array}{l}\text { Hacer uso de } \\
\text { materiales de } \\
\text { bajo impacto } \\
\text { ambiental }\end{array}$ \\
\end{tabular}

302 Energía

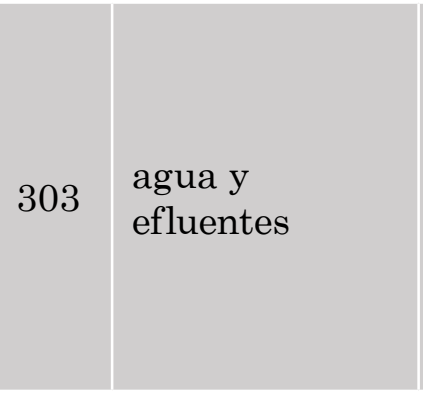

304 Biodiversidad

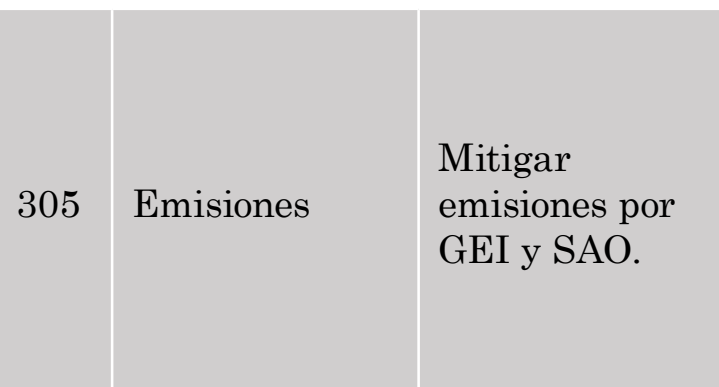

Efluentes y Residuos

\section{Determinar el} impacto de la empresa en la biodiversidad.

Disminuir el uso de energías no renovables en la empresa.

Disminuir el uso de agua y sus efluentes.

Disminuir los residuos generados por la empresa. impacto en el
Disminución del consumo de energía dentro de la organización, Reducciones en los requisitos de energía de productos y servicios

Valoración de las Interacciones con el agua como recurso compartido, Gestión de los impactos relacionados con la descarga de agua, Extracción de agua, Descarga de agua, Consumo de agua

Análisis de los sitios en áreas protegidas y áreas de alto valor de biodiversidad, Impactos significativos de actividades, productos $\mathrm{y}$ servicios en la biodiversidad

Mitigación de las Emisiones de GEI y Emisiones de sustancias que agotan la capa de ozono (SAO), Óxidos de nitrógeno (NOX), óxidos de azufre (SOX) y otras emisiones significativas al aire.

Identificación calidad y destino de la descarga de agua, Residuos por tipo y método de eliminación, Derrames significativos, Transporte de desechos peligrosos, Los cuerpos de agua afectados por las descargas de agua y / o escorrentía consumida

Pesaje de materiales reutilizados

m3 consumida en la organización.

Informe de biodiversidad.

Disminución de costos por agua.

Área: producción.

El uso de materiales es bajo y hay disminución en el impacto ambiental. Área: Investigación y

Disminución de costos por

Area: Investigación y Desarrollo

No afectación de la biodiversidad.

Área: producción.

Acomodaciones

físicas para

disminuir las emisiones.

Mejoramiento del aire. Área: producción. impacto de Desarrollo. energía.

\section{Cantidad} de residuos, contratos de residuos peligrosos.
Buena disposición final de los residuos. Área: producción. 


\begin{tabular}{|c|c|c|c|c|c|}
\hline ID & Indicador & $\begin{array}{c}\text { Objetivo } \\
\text { especifico }\end{array}$ & Acción & $\begin{array}{c}\text { Medio } \\
\text { verificación }\end{array}$ & $\begin{array}{l}\text { Impacto } \\
\text { esperado }\end{array}$ \\
\hline 307 & $\begin{array}{l}\text { Cumplimiento } \\
\text { ambiental }\end{array}$ & $\begin{array}{l}\text { Propender } \\
\text { por el } \\
\text { cumplimiento } \\
\text { de las leyes y } \\
\text { regulaciones } \\
\text { ambientales. }\end{array}$ & $\begin{array}{l}\text { Análisis del Incumplimiento } \\
\text { de las leyes y regulaciones } \\
\text { ambientales }\end{array}$ & $\begin{array}{l}\text { Cero Multas } \\
\text { o sanciones } \\
\text { ambientales. }\end{array}$ & $\begin{array}{l}\text { Cumplir con los } \\
\text { lineamientos } \\
\text { ambientales. } \\
\text { Área: } \\
\text { administración } \\
\text { y finanzas }\end{array}$ \\
\hline 308 & $\begin{array}{l}\text { Evaluación } \\
\text { ambiental del } \\
\text { proveedor }\end{array}$ & $\begin{array}{l}\text { Contratar con } \\
\text { proveedores } \\
\text { que } \\
\text { cumplan las } \\
\text { especificaciones } \\
\text { ambientales. }\end{array}$ & $\begin{array}{l}\text { Evaluación de ambiental del } \\
\text { proveedor }\end{array}$ & $\begin{array}{l}\text { Proveedores } \\
\text { seleccionados } \\
\text { con cero multas } \\
\text { o sanciones } \\
\text { ambientales. }\end{array}$ & $\begin{array}{l}\text { Mejoramiento } \\
\text { articulado de } \\
\text { los impactos } \\
\text { ambientales. } \\
\text { Área: } \\
\text { producción }\end{array}$ \\
\hline
\end{tabular}

Fuente: Elaboración propia.

En el estudio hecho por Yepes et al. (2015) se indica como sólo el $21 \%$ de los empresarios realizan inversiones en actividades de RSC y en su mayoría estas actividades se realizan de manera esporádica e intuitiva, lo cual no permite realizar un seguimiento a los impactos realizados por la inversión, que, para el caso concreto de las tres empresas valoradas, aplicaría lo evidenciado por Yepes et al. (2015).

Lo encontrado por Rodríguez y Ríos (2016) en cuanto al desempeño ambiental se orienta en gestión de materiales, energía, agua, biodiversidad, emisiones, transporte, cumplimientos regulatorios, residuos y vertimientos. Además, desarrollan programas ambientales que permiten minimizar los impactos negativos que genera su respectiva actividad productiva. Las empresas valoradas por el estudio también muestran este tipo de disposición hacia la falta de acciones más contundentes, por tanto, se hace la propuesta para que cada empresa inicie procesos con referente a la sostenibilidad ambiental (Tabla 5).

Igualmente (Rodríguez y Ríos, 2016), en cuanto al desempeño social las empresas valoradas en Colombia gestionan el talento humano, la seguridad industrial, la salud ocupacional, proveedores, inversiones en actividades de filantropía, iniciativas sociales, políticas de RSE e interacción con comunidades; ítems en los cuales las tres empresas creadas bajo el modelo de SBDC, requieren bastante trabajo y recursos humanos, físicos y económicos, para colocarlos en marcha. El plan de acción incluido en la Tabla 6, especialmente en lo referente a SST y nuevos empleos aclara como las empresas que fueron objeto de estudio se encuentran constituidas hace pocos años, y son microempresas, lo que de alguna forma justifica el bajo nivel de avance en términos de responsabilidad social y ambiental empresarial 
TABLA 6.

Acciones divulgaciones estándares sociales -400

\begin{tabular}{|c|c|c|c|c|c|}
\hline ID & Indicador & $\begin{array}{c}\text { Objetivo } \\
\text { especifico }\end{array}$ & Acción & $\begin{array}{c}\text { Medio } \\
\text { verificación }\end{array}$ & $\begin{array}{l}\text { Impacto } \\
\text { esperado }\end{array}$ \\
\hline 401 & Empleo & $\begin{array}{l}\text { Reportar } \\
\text { nuevos } \\
\text { empleos y } \\
\text { beneficios }\end{array}$ & $\begin{array}{l}\text { Reporte de las nuevas } \\
\text { contrataciones de empleados } \\
\text { y rotación de empleados, los } \\
\text { beneficios proporcionados a los } \\
\text { empleados a tiempo completo y } \\
\text { la licencia parental }\end{array}$ & $\begin{array}{l}\text { Contratos } \\
\text { de nuevos } \\
\text { trabajadores } \\
\text { y actas de } \\
\text { recibido de } \\
\text { beneficios. }\end{array}$ & $\begin{array}{l}\text { Mejoramiento } \\
\text { del empleo en } \\
\text { cantidad y calidad. } \\
\text { Área: Recursos } \\
\text { Humanos }\end{array}$ \\
\hline 402 & $\begin{array}{l}\text { Relaciones } \\
\text { laborales / de } \\
\text { gestión }\end{array}$ & $\begin{array}{l}\text { Comunicar } \\
\text { cambios } \\
\text { operacionales } \\
\text { en la empresa. }\end{array}$ & $\begin{array}{l}\text { Comunicación Períodos } \\
\text { de notificación mínimos } \\
\text { con respecto a los cambios } \\
\text { operacionales }\end{array}$ & $\begin{array}{l}\text { Comunicados } \\
\text { laborales } \\
\text { de cambio } \\
\text { operacional }\end{array}$ & $\begin{array}{l}\text { Mejora ambiente } \\
\text { laboral en las } \\
\text { operaciones. } \\
\text { Área: Recursos } \\
\text { Humanos }\end{array}$ \\
\hline
\end{tabular}

\begin{tabular}{|c|c|c|c|c|c|}
\hline 403 & $\begin{array}{l}\text { Seguridad y } \\
\text { salud laboral }\end{array}$ & $\begin{array}{l}\text { Implementar } \\
\text { un SST en la } \\
\text { empresa. }\end{array}$ & $\begin{array}{l}\text { Implementación del } \\
\text { Sistema de gestión de la } \\
\text { salud y la seguridad en } \\
\text { el trabajo, identificación } \\
\text { de peligros, evaluación de } \\
\text { riesgos e investigación de } \\
\text { incidentes, Capacitación de } \\
\text { los trabajadores sobre SSL, } \\
\text { Promoción de la salud del } \\
\text { trabajador, Prevención y } \\
\text { mitigación de los impactos } \\
\text { de SS ocupacional, } \\
\text { Trabajadores cubiertos por } \\
\text { un sistema de gestión de } \\
\text { SS ocupacional, reporte de } \\
\text { lesiones relacionadas con el } \\
\text { trabajo, reporte de enfermedad } \\
\text { relacionada con el trabajo. }\end{array}$ & $\begin{array}{l}\text { Certificado } \\
\text { de ARL en el } \\
\text { cumplimiento } \\
\text { de SST. }\end{array}$ & $\begin{array}{l}\text { Propender por la } \\
\text { seguridad y salud } \\
\text { en las personas } \\
\text { que laboran } \\
\text { en la empresa. } \\
\text { Disminución de } \\
\text { riesgos laborales } \\
\text { para el trabajador. } \\
\text { Área: Recursos } \\
\text { Humanos }\end{array}$ \\
\hline 404 & $\begin{array}{l}\text { Entrenamiento } \\
\text { y educación }\end{array}$ & $\begin{array}{l}\text { Capacitar y } \\
\text { evaluar a los } \\
\text { empleados de } \\
\text { la empresa. }\end{array}$ & $\begin{array}{l}\text { Capacitación por año por } \\
\text { empleado, Programación para } \\
\text { mejorar las habilidades de } \\
\text { los empleados, determinación } \\
\text { los empleados que reciben } \\
\text { evaluaciones regulares de } \\
\text { desempeño y desarrollo } \\
\text { profesional }\end{array}$ & $\begin{array}{l}\text { Certificados de } \\
\text { capacitación y } \\
\text { evaluaciones } \\
\text { de desempeño. }\end{array}$ & $\begin{array}{l}\text { Mejor rendimiento } \\
\text { laboral en los } \\
\text { empleados de la } \\
\text { empresa. } \\
\text { Área: Recursos } \\
\text { Humanos }\end{array}$ \\
\hline 405 & $\begin{array}{l}\text { Diversidad e } \\
\text { igualdad de } \\
\text { oportunidades }\end{array}$ & $\begin{array}{l}\text { Propender por } \\
\text { la equidad } \\
\text { entre mujeres } \\
\text { y hombres } \\
\text { dentro de la } \\
\text { organización. }\end{array}$ & $\begin{array}{l}\text { Diversificación de órganos } \\
\text { de gobierno y empleados, } \\
\text { mantener las relación } \\
\text { entre el salario básico y la } \\
\text { remuneración de las mujeres } \\
\text { con los hombres. }\end{array}$ & $\begin{array}{l}\text { Constancias de } \\
\text { remuneración } \\
\text { igual trabajo } \\
\text { igual } \\
\text { remuneración } \\
\text { entre sexos. }\end{array}$ & $\begin{array}{l}\text { Valoración del } \\
\text { trabajo de la } \\
\text { mujer dentro de la } \\
\text { empresa. } \\
\text { Área: Recursos } \\
\text { Humanos }\end{array}$ \\
\hline 406 & $\begin{array}{l}\text { No } \\
\text { discriminación }\end{array}$ & $\begin{array}{l}\text { Eliminar la } \\
\text { discriminación } \\
\text { de toda índole } \\
\text { en la empresa. }\end{array}$ & $\begin{array}{l}\text { Disminución de los Incidentes } \\
\text { de discriminación y acciones } \\
\text { correctivas tomadas. }\end{array}$ & $\begin{array}{l}\text { Cero } \\
\text { denuncias por } \\
\text { discriminación } \\
\text { en la empresa. }\end{array}$ & $\begin{array}{l}\text { Contribución } \\
\text { a un país más } \\
\text { equitativo y menos } \\
\text { discriminativo. } \\
\text { Área: Recursos } \\
\text { Humanos }\end{array}$ \\
\hline
\end{tabular}




\begin{tabular}{|c|c|c|c|c|c|}
\hline ID & Indicador & $\begin{array}{c}\text { Objetivo } \\
\text { especifico }\end{array}$ & Acción & $\begin{array}{c}\text { Medio } \\
\text { verificación }\end{array}$ & $\begin{array}{l}\text { Impacto } \\
\text { esperado }\end{array}$ \\
\hline 407 & $\begin{array}{l}\text { Libertad de } \\
\text { asociación y } \\
\text { negociación } \\
\text { colectiva }\end{array}$ & $\begin{array}{l}\text { Permitir a los } \\
\text { trabajadores } \\
\text { en la empresa } \\
\text { ejercer su } \\
\text { derecho } \\
\text { a la libre } \\
\text { asociación y } \\
\text { negociación. }\end{array}$ & $\begin{array}{l}\text { Propender para que las } \\
\text { operaciones y proveedores en } \\
\text { los que el derecho a la libertad } \\
\text { de asociación y negociación } \\
\text { colectiva puede estar en } \\
\text { riesgo. }\end{array}$ & $\begin{array}{l}\text { Conformación } \\
\text { de sindicatos, } \\
\text { juntas o } \\
\text { comités. }\end{array}$ & $\begin{array}{l}\text { Respeto por los } \\
\text { derechos de los } \\
\text { trabajadores. } \\
\text { Área: Recursos } \\
\text { Humanos }\end{array}$ \\
\hline 408 & $\begin{array}{l}\text { Trabajo } \\
\text { infantil }\end{array}$ & $\begin{array}{l}\text { Eliminar } \\
\text { el trabajo } \\
\text { infantil en la } \\
\text { empresa. }\end{array}$ & $\begin{array}{l}\text { Eliminación en las operaciones } \\
\text { y proveedores con riesgo } \\
\text { significativo de incidentes de } \\
\text { trabajo infantil }\end{array}$ & $\begin{array}{l}\text { Cero reporte } \\
\text { niños } \\
\text { trabajando en } \\
\text { la empresa. }\end{array}$ & $\begin{array}{l}\text { Respeto por los } \\
\text { derechos de los } \\
\text { niños. } \\
\text { Área: Recursos } \\
\text { Humanos }\end{array}$ \\
\hline 409 & $\begin{array}{l}\text { Trabajo } \\
\text { Forzado u } \\
\text { Obligatorio }\end{array}$ & $\begin{array}{l}\text { Eliminar el } \\
\text { trabajo forzado } \\
\text { en la empresa. }\end{array}$ & $\begin{array}{l}\text { Disminución en las } \\
\text { operaciones y proveedores } \\
\text { con riesgo significativo de } \\
\text { incidentes de trabajo forzado u } \\
\text { obligatorio }\end{array}$ & $\begin{array}{l}\text { Cero reporte } \\
\text { de personas } \\
\text { con trabajo } \\
\text { forzado. }\end{array}$ & $\begin{array}{l}\text { Respeto por la } \\
\text { dignidad de las } \\
\text { personas. } \\
\text { Área: Recursos } \\
\text { Humanos }\end{array}$ \\
\hline 410 & $\begin{array}{l}\text { Prácticas de } \\
\text { seguridad }\end{array}$ & $\begin{array}{l}\text { Capacitar } \\
\text { en derechos } \\
\text { humanos. }\end{array}$ & $\begin{array}{l}\text { Capacitación al Personal } \\
\text { de seguridad en políticas o } \\
\text { procedimientos de derechos } \\
\text { humanos }\end{array}$ & $\begin{array}{l}\text { Cero reportes } \\
\text { de infringir } \\
\text { los derechos } \\
\text { humanos. }\end{array}$ & $\begin{array}{l}\text { Respeto por los } \\
\text { derechos humanos. } \\
\text { Área: Recursos } \\
\text { Humanos }\end{array}$ \\
\hline
\end{tabular}

Fuente: Elaboración propia.

\section{Conclusiones}

En general las empresas asesoradas por SBDC presentan debilidades importantes, que requieren mejorar en todas las áreas y en los dos aspectos de la responsabilidad social empresarial, es por ello la importancia de realizar una propuesta que permita mejorar los procesos llevados a cabo en las tres organizaciones. A pesar de las altas amenazas que evidencian las empresas, también se reconocen oportunidades que pueden aportar el desarrollo empresarial dentro del entorno. Especialmente las basadas en el aporte técnico y organizacional en entes gubernamentales, lo cual ha hecho que siempre estén en contacto con proyectos que permiten el mejoramiento continuo.

Se realiza una propuesta de estrategias para mejorar las debilidades, mantener las fortalezas, minimizar las amenazas y aprovechar las oportunidades, con el fin último de que las empresas puedan optimizar su competitividad con responsabilidad social y ambiental. Igualmente se genera una serie de indicadores por áreas de trabajo y por estándares globales, hechos para medir el nivel de mejoramiento en razón de las debilidades, fortalezas, amenazas y oportunidades detectadas en el diagnóstico y el cumplimiento o no de los estándares internacionales; con lo cual se pretende que sea el insumo para dar paso a un reporte profundo en los temas sociales y ambientales de las empresas, a través de los informes de sostenibilidad.

La realización de acciones de RSE con base en los estándares GRI, aunque requiere de una alta inversión de recursos humanos, físicos y económicos, les permite a las empresas generar mayor competitividad mediante procesos de innovación con una visión responsable de una sociedad más equitativa y un ambiente más sano. 
Es importante que las MyPE's vean en la responsabilidad social y ambiental una oportunidad para mejorar su competitividad, desarrollen sus prácticas responsables en cuanto a problemas sociales y ambientales de la comunidad, y la posibilidad de vender a empresas grandes donde tienen mayor impacto. Igualmente el estudio permitió que las empresas dimensionen su entorno externo e interno a través de la DOFA estratégica, con el fin último de la búsqueda de desarrollo sostenible, que integre la parte ética y técnica, en engranaje con los stakeholders, para generar identidad y confianza en la comunidad local, proyectada hacia el crecimiento de las empresas.

\section{REFERENCIAS}

Bour, E. (2012.). Responsabilidad Social de la Empresa Análisis del Concepto. Estudios Económicos, 29(59), 1-30.

Chumaceiro, A., Hernández, J. y Chirinos, E. (2016). Responsabilidad social universitaria, desarrollo sostenible y ciudadanía ambiental. Cuadernos de RSO, 4(1), 53-64

Del Castillo, C., Cancino, A., Martínez, F. \& Corona, C. (2013). Reporte No Financiero de la Gestión Empresarial: Casos del Global Reporting Initiative en Chile. Interciencia, 38(4), 260-266. Recuperado de https:// www.interciencia.net/wp-content/ uploads/2017/12/260-CANCINO-7.pdf

Fernández, M. F. y Larrinaga, C. (2007). Memorias de sostenibilidad: responsabilidad y transparencia. Contaduría Universidad de Antioquia, 51, 89-104. Recuperado de http://aprendeenlinea.udea.edu.co/revistas/index. php/cont/article/view/2149
Gómez, M. y Quintanilla, D. (2012). Los informes de responsabilidad social empresarial. Cuadernos de Contabilidad, 13(32), 121-158. Recuperado de https:// revistas.javeriana.edu.co/index.php/ cuacont/article/view/3894

González, R., Galeano D. H. y Trejos, L. (2015). Estados Unidos en la política exterior colombiana: ¿aliado incondicional? Económicas CUC, 36(1), 43-56. Recuperado a partir de https://revistascientificas.cuc.edu.co/economicascuc/ article/view/672

GRI, Global Reporting Initiative (2018) Sustainability Reporting Guidelines. Recuperdo de: www.globalreporting.org

Haro, A., Alarcón, F. y Caba, M. (2012). Los determinantes de la divulgación de información sobre responsabilidad social corporativa en el sector financiero: el caso español. Revista Facultad de Ciencias Económicas: Investigación y Reflexión, 20(1), 189-205. http://dx.doi. org/10.18359/rfce.2192

Pérez, C. Haro, A., Saraite, L. y Gálvez, M. (2016). La industria farmacéutica ante la demanda de responsabilidad social corporativa. Perspectiva Empresarial, 3(1), 55-75. http://dx.doi. org/10.16967\%2Frpe.v3n1a1

Ponce, H. (2007). La Matriz FODA: Alternativa de diagnóstico y determinación de estrategias de intervención en diversas Organizaciones. México, D.F.: Escuela Superior de Comercio y Administración, Unidad Santo Tomas.

Rebelo, J. \& Marques, M. (orgs.)(2016). Desafíos para a gestão de Recursos humanos no séc. XXI: Tendências, estrategias e Práticas. VI conferência de Investigação e intervenção em Recursos humanos. Fevereiro 18 - Abril 19, Instituto Politécnico de Setúbal. Setúbal, Portugal. 
Reyes, I., Hernández, J., Chumaceiro, A. y Cadrazco, C. (2016). Epilepsia un abordaje social: experiencia de sensibilización y concientización ciudadana. Orbis, 35(12), 58-76. Consultado de http://ojs.revistaorbis.org.ve/index.php/orbis/article/view/33

Rodríguez, L. y Ríos, L. (2016). Evaluación de sostenibilidad con metodología GRI. Dimensión Empresarial, 14(2), 73-89. https://doi.org/10.15665/rde.v14i2.659

Silva, D. (2009). Teoría de Indicadores de Gestión y su Aplicación Práctica. [Online]. Bogotá, D.C.: Universidad Militar Nueva Granada. Recuperado de https://www. umng.edu.co/documents/10162/1299317/ ART_29.pdf

Silva, F. \& João, R. (2012). Una propuesta de indicadores y un informe de sustentabilidad basada en el Global Reporting Initiative para empresas hoteleras. Estudios y Perspectivas en Turismo, 21(1), 68-87.

Sisiruca, M. y Salazar, C. (2014). Valores éticos de la responsabilidad social interna e Vélez $\mathrm{n}$ centros de producción audiovisual. Económicas CUC, 35(1), 79-90.

Vélez, A. (2011). Un Recorrido Hacia La Responsabilidad Social Corporativa. Revista Ciencias Estratégicas, 19(25), 55-74.

Vives, A. y Peinado-Vara, E. (eds.) (2011). La Responsabilidad Social de la Empresa en América Latina. Washington, D.C.: Fondo Multilateral de Inversiones (Banco Interamericano de Desarrollo). Recuperado de https://www.pwc.com/cl/es/publicaciones/assets/la-responsabilidad-social-dela-empresa-en-america-latina.pdf

Yepes, G. et al. (2015). Estado de la RSE en Colombia - Percepción, Práctica e Impacto en el Negocio. Avances de Entorno de Negocios No. 20. Bogotá, D.C.: Universidad Externado de Colombia. Disponible en http://administracion.uexternado.edu. co/PRME/memorias/Entorno\%20de\%20 los\%20Negocios\%20N\%2020.pdf

\section{Biodata}

Alba Patricia Guerrero Guerrero es Ingenieria Agroindustrial, líder del Centro de Desarrollo Empresarial (Emprendimiento y Empresarismo) en el Servicio Nacional de Aprendizaje-SENA (Tumaco, Colombia) con maestria en Administracion de Organizaciones y Especializacion en Gerencia de Proyectos. https://orcid.org/0000-00034222-702X 